\title{
DEVELOPMENT OF CRITICAL THINKING SKILLS: COMPARATIVE ANALYSIS OF MEDIA LITERACY LEVEL IN BOSNIA AND HERZEGOVINA AND LATVIA
}

\author{
Sandra Murinska-Gaile \\ Rezekne Academy of Technologies, Latvia \\ Sabahudin Hadžialić \\ International University Travnik, Bosnia and Herzegovina
}

\begin{abstract}
The aim of this paper is to look on level of media literacy and activities in this field in two countries - Latvia and Bosnia and Herzegovina. People are exposed to a flow of diverse content of information and opinions, there it is important to discuss about media education and it's outcome - the media literacy. Media literacy helps people to analyze, evaluate, and create messages thus develops people's critical and creative abilities. The survey about credibility of mass media, critical use of information, understanding of media literacy in each country, institutions promoting media literacy and the impact of media literacy on political decision making was carried out.

The main hypothesis of this case study was that media literacy is basic presumption of the establishing the critical thinking of society of developed democratic consciousness. The comparative analysis showed that sociological aspect in the area of Bosnia and Herzegovina within the deep division in the society itself, with the lack of consensual awareness creates presumption trust completely into the mass media, while in the case of Latvia there is just few answers related to the existing media literacy.
\end{abstract}

Keywords: critical thinking, democracy, media literacy, survey, political manipulation.

\section{Introduction}

The explosion of fake news, mass media coverage, information flows create a reality for the majority of society, thus showing how they should live and whom they should believe. People are exposed to a flow of diverse content of information and opinions, and that is why is important to discuss about media education and it`s outcome - the media literacy. Media literacy helps people to analyze, evaluate, and create messages while developing people's critical and creative abilities.

UNESCO (Media studies in education, 1977) was, yet in the seond half of XX century, started an question of education about the way (how to) of ,reading“ of the media. Based on the idea of importance which media play in the life of 
individuals, families and the wider community, UNESCO has asked that on international level should meet the scientists to explore the ways how to incorporate media education into the educational systems of all developed or less developed, countries. (Turčilo \& Tajic, 2014). Since the signing of the Declaration on Media Education (1982) until today, the concept of media literacy or media education somewhat has slightly changed, but remained basically on the foundation idea - communication rights that are arising from the basic human rights which are guaranteed by international community documents, and before only the United Nations Charter on human rights (1945) and the European Convention on human rights and fundamental freedoms (1950).

The aim of this paper is to look on media literacy activities in two countries Latvia and Bosnia and Herzegovina because the academic institutions from both countries (Rezekne Academy of Technologies and International University Travnik) have collaboration in media and communication field.

More and more attention is being paid to media literacy in Latvia. Latvian University Faculty of Social Sciences in cooperation with the UNESCO LNC has established UNESCO Media and Information Department, activities on media literacy research are being realized at other institutions as well. Media literacy is no longer separable from education. This year will start work on a new approach to competence-based education model in Latvia. The project is intended to develop and approve a new curriculum in general education - children of one and a half year of age up to secondary education - and launch a successor of this approach to education. The subjects system will continue, but it will be divided into six basic competences and transversal competencies. Transversal competencies will be present in each of the core competencies. Transversal competencies are:

- Critical thinking and problem solving;

- Creativity, initiative and entrepreneurial ability;

- Digital and media;

- Self-knowledge, self-direction and learning how to learn;

- Co-operation;

- Participation (Source: The Ministry of Education and Science of Latvia, 2016)

As can be seen the competency is: critical thinking and digital and media expertise. Critical thinking is one of the main characteristics of media literacy: in an age of increased reliance on digital and social media across all age groups for information and communication needs citizens must be able to critically access and analyze a constant and diverse stream of information on which to base their democratic participation Mihailid, Thevenin, 2013). 
This is not the only decision and direction of actions within which it is planned to develop media literacy in Latvia. Latvian media policy have been confirmed (2016) in regards 2016 - 2020 guidelines. According to the guidelines one action line will be focus on media literacy.

Media education development in Latvia is still characterized as problematic when talking about media environment and public space. Researchers state that media development has not been able to provide sufficiently good examples of good journalism and media practice that could serve as milestones for defining media quality criteria. Media critique is weakly developed therefore there are limitations for having rational and critical debates on media nature and their mission in the public space (Brikše, Friebergs, \& Spurava, 2014). Thus, the development of both sides is still on the road to full-fledge information creation, distribution and consumption practices. Authors of Latvian media policy guidelines 2016 - 2020 have concluded that nevertheless media usage habits of the Latvian population remaining stable, there has been gradually lost confidence in mass media. Residents are critical to the quality of the content of media, believing that media owners affect the content of mass media and it is of lower quality. Similarly, society thinks that the media has strengthened the view of government, rather than the population. This image informs about the media and public alienation. At the same time habits of most popular media usage show audiences sustainability by using them mostly for entertainment purposes (Latvian media policy guidlines 2016 - 2020, 2015). It means it is a question about trust in media and responsibility of journalists.

The Press Council in Bosnia and Herzegovina recently launched an online platform featuring a wide-range of video classes on media ethics and available free of charge in local language or English with subtitles (see www.mediaethics.eu). The setting-up of this online media ethics school has been supported by UNESCO within the framework of the project "Building Trust in Media in South East Europe and Turkey" (UNESCO, 2016).

At the same time exist a direct connection between politics and the media within the possible assumption of all forms of manipulation of awareness, understandings and possible conclusions, through the creation of mediocracy (Meyer, 2002), in other words - media democracy, where we do not know any more, or are not able to know how much politics leads media or vice versa, how the media control and direct the politics and creates a new reality that often adjoin with virtual forms of assumptions of the possible solutions focused on negation of democracy, or democratorship, as the co-author of this paper have called, within his essays, both in domestic and in foreign media, form of social order in which Bosnia and Herzegovina exists since 1990.

Political pluralism of modern Bosnian and Herzegovinian society could well be an advantage oriented towards quality development of the consociational 
awareness (Kasapović, 2005) of all its citizens and people(s), but only under the condition that, in the context of the development of a healthy society of direct democratic awareness, with common, adjusted efforts of all stakeholders that creates a Bosnia and Herzegovina reality, find a modus vivendi that not even in any moment will violate the right of another and different one for their own survival and incidence within the society. The freedom of other and different ones stops at the moment when "my" freedom threatens the freedom of others and different ones" (Hadžialić, 2013). Overcoming the above is, from the sociological - communication aspect of the satisfying development of a healthy society of direct democratic consciousness, and one of the main hypothesis of this paper, with the analysis of the research project, in the example of case study called "Media (i)literacy and political manipulation - position and opposition in the context of the development and / or preventing the development of a healthy society of direct democratic consciousness - advantages and disadvantages of Bosnia and Herzegovina and Latvia"- where the primary objective of the study was evaluation and comparison of levels of media literacy in Latvia and Bosnia and Herzegovina within the context of political manipulation (IUT-RAT, 2016) ${ }^{1}$.

\section{Media literacy as opposite to harmful effects of mass media}

Media literacy carries, within it, a double meaning - as the term is defined as the ability to access, analyze, evaluate and transmits the messages through the media while the essential focus of media literacy is mastering of critical and creative skills, knowledge that are helpful to link and connect complex ideas, constantly questioning the appearances of it, try to identify answers that will satisfy the congenital curiosity of each of us, but also to identify the individual, but also the wider social misconceptions.

In the case of the above mentioned we are focused on the concept of media literacy, which is based on the media as a positive source of information - aimed towards shaping of a positive manipulation, and not with the "alternative facts" (Hadžialić, 2017), of maintaining, shaping and developing of the society of good intentions and interests intertwined by all for all goals, and not towards negative manipulation of shaping, maintaining and developing of the society of targeted direction for satisfying the individual and / or a small group of party / party intents and interests of all for one and / or one for all.

\footnotetext{
${ }^{1}$ As continuance of cooperation between Rezekne University and International University Travnik, Sandra Murinska Gaile and Sabahudin Hadžialić and agreed in developing another research, with the support of rectors of our Universities, so in 2017 we plan to start another joint project titled: "The literacy of the mass media and technologies in the teenage consumer-education“.
} 
Definitions of media literacy emphasize building skills to become more mindful media consumers capable of navigating complex media landscapes (Vraga \& Tully, 2016). The fundamental objective of media literacy within this definition is a 'critical autonomy relationship to all media' organized around a set of common beliefs or precepts, which recognize that the media are constructed and that they have wide commercial, ideological and political implications (O'Neill, 2010). The media today influence the shaping of opinions, beliefs and attitudes. The ability to understand and perceive the surrounding information directly affects the person's quality of life. Because the person is able to look at the various aspects of the matter, the effects of control, thus without considering the situation used only black or white attitude. Democratic participation asks form person to be able to understand broader social, cultural, and political contexts. It is necessary that citizens act as critical thinkers. Within the moment when we understand exactly influences of the media, with the help of media literacy, we are on a good path to prevent dependence on the media, or, in other words, to use them as a tool for making judgments and attitudes within the creation of a healthy society of direct democratic consciousness, and not the main course on the table of bad manipulations of individual or, again, in other words, narrow group interests and intentions in Bosnia and Herzegovina.

The vital role of information in the development of democracy: cultural participation and active citizenship also justifies it (Koltay, 2011). It shows that the need for media literacy is important for media field /journalists as well. Media literacy highlights journalists responsibility of information producing, availability of sources, independency and diversity of opinions. Journalists and content they made are impulse to look on problem or question broader and to act as a mediators in social, political issues representing them to society. Time of different technologies and mass media give a lot of possibilities for engaged and active civic participation.

Although there are differences in the degree of influence of the media, all media experts agree that the media certainly affect society as a whole, and thus $e o$ ipso and to each individual and his / her immediate environment.

Media literacy enables primarily children, future citizens - political choices, understanding of political discourse and participation within it. In this way, as a mature, media literate, well-informed citizens will be able to make their own decisions about the democratic electoral process. By understanding of the impact of media on society, media literacy prevents us to become dependent on the media. Or to at least to enable us to control the selection method, the method of reading and making appropriate decisions based on the "reading" of the media that are available to us. In learning to critically read media messages, citizens are developing the abilities to gather accurate, relevant information about their society 
and to question authority (both textual and, by implication, institutional) (Mihailidis \& Thevenin, 2013).

The need for such research exists not only in transition countries such as Bosnia and Herzegovina, but also in post-transition countries such as Latvia due to the fact that because of the new media and the availability of different information to everyone at any time and in any way possible within the multimedia availability of new media, research certainly shows how much more need to be done on improving the education of all individuals, regardless of their social, racial, ethnic, and / or political status, and above all because of the society which aims towards further development of direct and immediate democratic consciousness.

\section{Data Organization and Analysis}

Survey was realized and data was collected through online survey platform (surveymonkey.com). The analysis was carried out in Bosnia and Herzegovina on sample of 186 respondents and in Latvia between 130 and 136, depending on an answered question. Having in mind that it is methodologically relevant to analyze a research successfully on the basis of $5 \%$ successfully replied answers, this research has been efficiently realized, because in Bosnia and Herzegovina it has reach $62 \%$ of rate and in Latvia between $43 \%$ and $45 \%$ within replies, depending of the questions and within causal - interaction relations and ethnic belongings that satisfies planed number of interviewed people.

The age of most respondents was 19-29 in Latvia and 19-29 and 30-65 in Bosnia and Herzegovina (see Figure 1). So the data displays opinion of early adulthood (byJeffrey Jensen Arnett), taking into account that the emerging adulthood which encompasses early adulthood are years of great instability, identity explorations, self-focus, feeling in between, possibilities/optimism (Arnett, 2014). Of course there is diversity in culture, economics and social situation but the characteristics analysing responses should be takan into account. Still it is a time of the period of the life of active decision making and in the context of this research media users, too. For example, age of years 15-29 have the highest number of Internet users in Latvia in 2016 (TNS, market, public opinion and media research agency in Latvia, 2016). 
Proceedings of the International Scientific Conference. Volume II, May $26^{\text {th }}-27^{\text {th }}$, 2017. 504-518

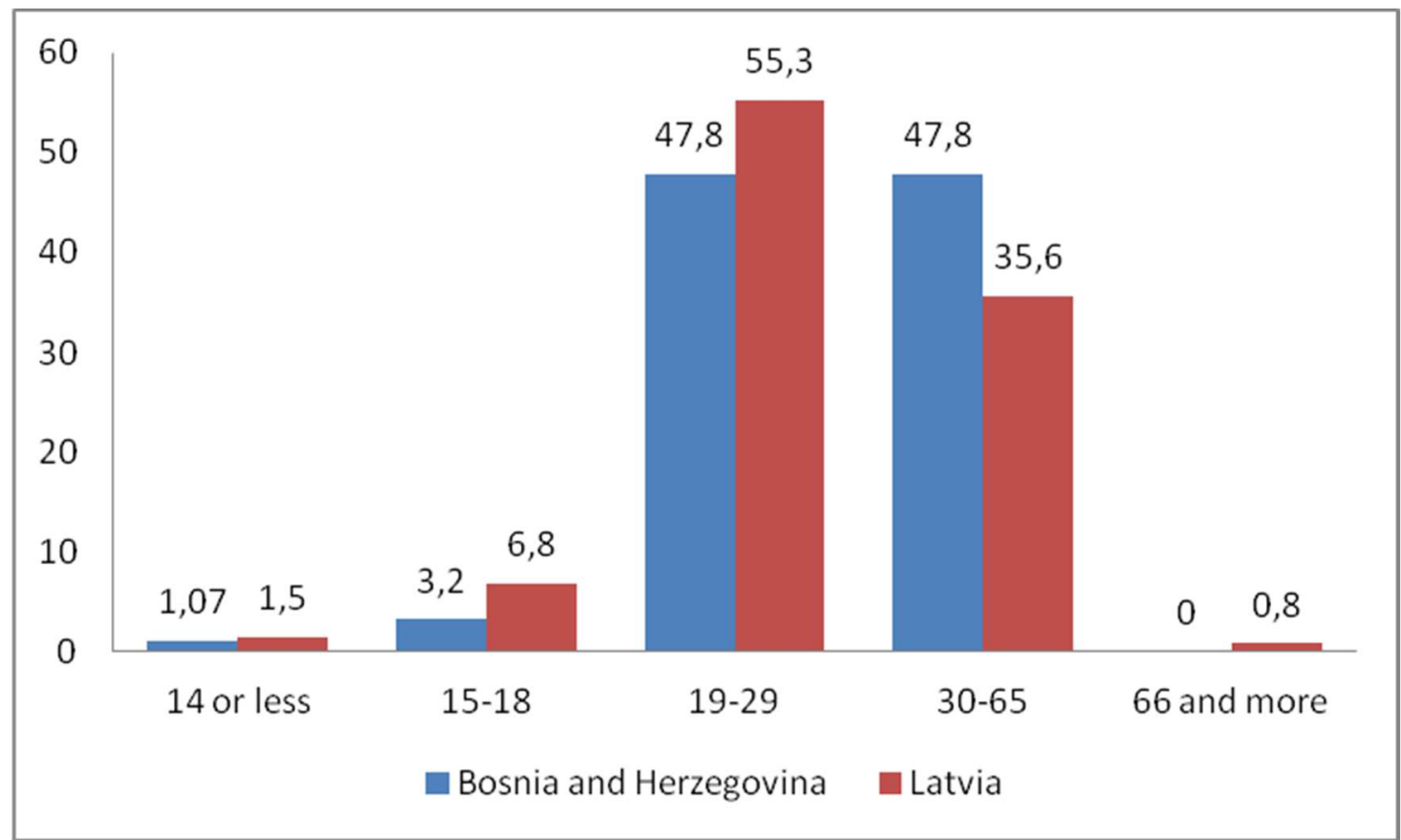

Figure 1 Age of Respondents

The table (Figure 2) show that among 186 respondents in Bosnia and Herzegovina 78 or $41,9 \%$ were females and 108 or $58,0 \%$ were males. In Latvia 95 or $73,1 \%$ were female and 35 or $26,9 \%$ were males. It shows the inequality in gender activity and impact on decisions making in both countries.

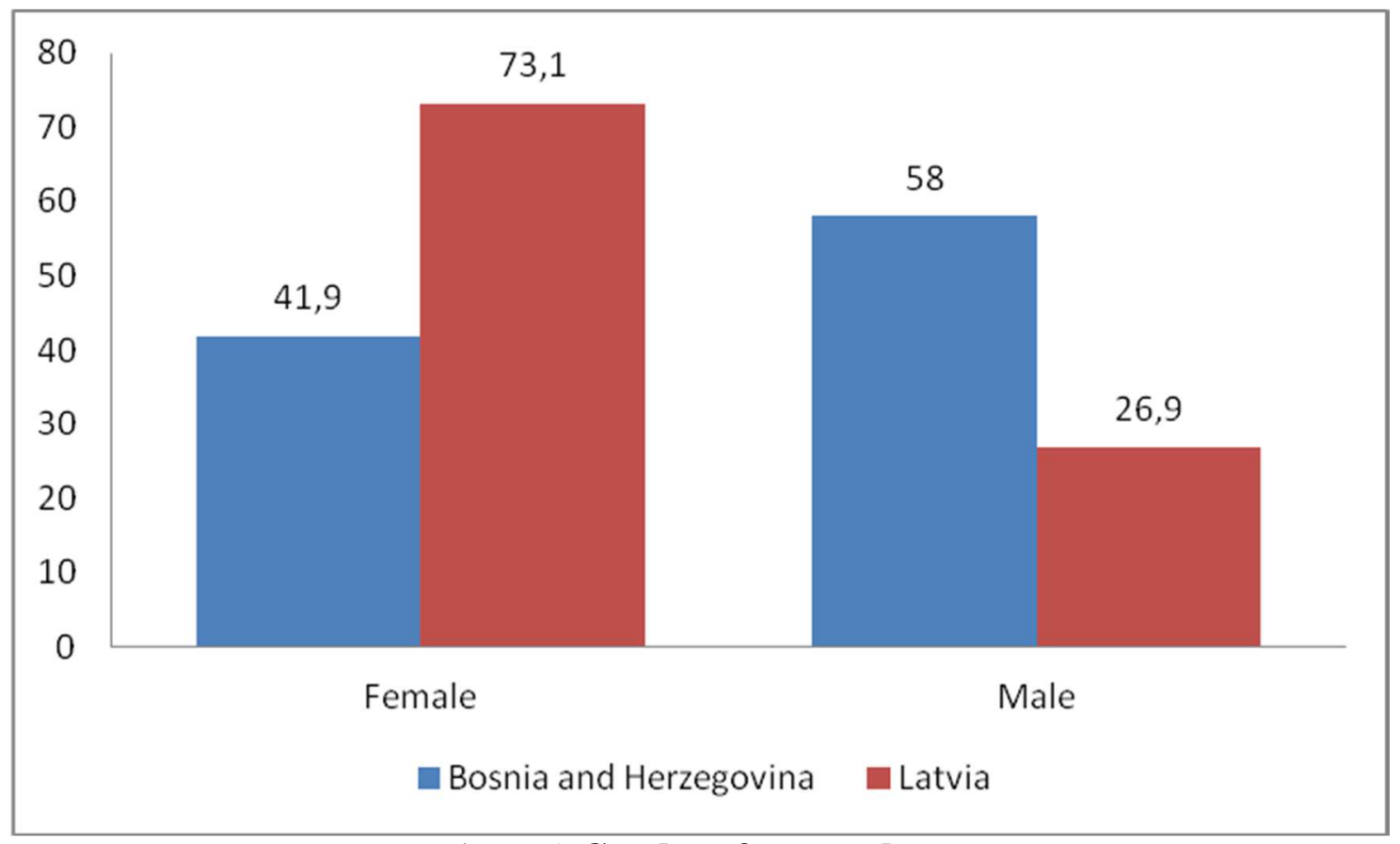

Figure 2 Gender of respondents 
The questionnaire consists of 18 questions on the grounds of which the main tendencies of media literacy in Latvia and Bosnia and Herzegovina were stated analyzing such issues:

a) Credibility of mass media;

b) Critical use of information;

c) Understanding of media literacy in each country;

d) Institutions promoting media literacy;

e) The impact of media literacy on political decision making.

At first were made data analysis in each country, than the comparative analysis was carried out taking into account context of the each state. The difficulties encountered in the amount of respondents - in Latvia some respondents didn `t give answers to all questions.

\section{Results}

Within the deep division in the society itself, sociological aspect in the area of Bosnia and Herzegovina, with the lack of consensual awareness creates presumption trust completely into the mass media, while in the case of Latvia there are just few answers related to the existing media literacy. Although, through comparative method, we are faced with almost exactly same answers that are targeting towards reliable inductive conclusions that here we are talking about oneness of directions, with the exception of the first possibility, understanding of the appearances of mass media. Also, it is indicative that number of those people who consider that mass media are authentic source of information are much bigger in Bosnia and Herzegovina $(6,5 \%)$ than in Latvia $(0,7 \%)$.

Although very often in conflict with certain modalities within presented survey, very often analyses and synthesis within certain questions creates presumptions of the importance of social assumptions of understandings of authenticity of the certain sources of information when we are talking about mass media.

Percentage of those who consider that mass media are authentic source of information within given analyses in Bosnia and Herzegovina, is, conditionally taken, big, while, within comparative analyses with Latvia, in disproportion, because in $\mathrm{BiH}$ there is sociological set-up of assumed manipulation on the side of $\mathrm{BiH}$, having in mind the level of educational consciousness who believes "their" mass media (you should read this as:"ethnical") that is manifested on the example of old nanny and her words "it is truth - it was on TV" which shows the lack of exact critical observation of the media and lack of media literacy when is in question checking out of media accuracy of certain information. Because of bigger level of media literacy on the side of Latvia is higher presence of checking out. 
Bosnia and Herzegovina is the country of many contradictions, so we cannot be surprised that $39,3 \%$ (79 out of 186) does not feel relaxed with existing media, while $38,7 \%$ (72 out of 186) partially agree, having in mind the number of those who does not trust the authenticity of the information source of existing mass media, while the percentage of those in Latvia is on the lower level of set-up of $27,6 \&$ (37 out of 136) although they are on aproximatelly same level of set-up with $\mathrm{BiH}$ when distrust and authenticity of mass media is in question. Although we can make conclusion that on the basis of previous question we have the same level of appearance of media literacy, still we can see differences here because in Bosnia and Herzegovina 10,2 \% (19 out of 186) feels completely relaxed with existing media while in Latvia that percentage is extremely higher and goes up to $51,5 \%$ (69 out of 136) which might be indicative for the beginning of understandings of unity of diversity at media literacy.

Namely, with presumption that developed society have developed media literacy within all shapes of manifestation, it is obvious that the number of those who feels relaxed with existing media in Latvia in Latvia exactly meet the assertion that political manipulation through media texts/articles in any shape less expressed in this Baltic country than in Bosnia and Herzegovina.

In regards the question of importance of knowing who is author of the information/media text, almost similar percentage of those who are completely agree or just agree with certain imperceptible objections and comprehensive awaraness of interviewed ones (Bosnia and Herzegovina - 26,3\% - 49 out out of 186; Latvia 43,7 \% - 59 out of 136 and/or in Bosnia and Herzegovina 45,2 \% - 84 out of 186 and in Latvia 44,4\% - 60 out od 136), although the question itself was with suggestive nature with the goal of provocation of the possible answers. Although, the fact is that for bigger number of interviewed ones in Bosnia and Herzegovina (17,2 \% - 32 out of 186) in relations to Latvia (5,9\% - 8 out of 136), it is irrelevant who is author of the information/text talks more about the situation which is suitable for the area of sociological shape reflected through the expression "I do not care", or in another words - to the persons to whom is "foreign" media literacy - critical observation of presented media texts/articles of all kind of shapes.

On the question "Do you consider yourself media literate person?" it is interesting on a simple level of understandings (of all shapes of media appearances with the use of Internet for the complete informing without getting into the concrete understanding which kind and in which way, through the checking out, we are using) of deep division as it is in Bosnia and Herzegovina goes so far that raise up to $47,3 \%$ (88 out of 186) when we have in Latvia only $19,7 \%$ (26 out of 132) tells only one thing - in Bosnia and Herzegovina we do not have enough understanding, but also a lack o media literacy as well. 
Almost $50 \%$ of interviewed people in Bosnia and Herzegovina (48,9 \% - 91 out of 186) in comparison with 33,3\% (45 out 135) in Latvia has a doubt in accuracy and authenticity of presented information, but however, if we take into the account the lack of media literacy in Bosnia and Herzegovina more than in Latvia, the scientific conclusion might be directed towards on expressed dissatisfaction with overall situation within the society from the side of interviewed ones and in the same time also dissatisfaction with media articles of all kinds of shapes presented to them, because that percentage, in the healthy society of immediate democratic consciousness, would be extremely smaller, targeting the wellbeing of the society as the whole and not exclusively of its certain parts only.

On a question to which kind of media you trust mostly, another very suggestive question, the answers were pretty similar on both sides (In Bosnia and Herzegovina - 55,4 \% - 105 out of 186 and in Latvia - 45,9\% - 62 out 135) and this shows more sociological-psychological frame of every individual and it was pretty much directed towards egocentrism of trusting only "my own judgment", and how it is possible in Bosnia and Herzegovina where Media literacy within overall manifestation on extremely low level? That is exactly why is possible to underline that shaped up media literate person (in other words also within the situation where all participants of media communication within its all totality equally media literate) surely have more trust in media, because all involved would targeting general good as priority.

The fact that 17,2 \% (32 out of 186) in Bosnia and Herzegovina in comparison with Latvia where is $8,9 \%$ (12 out of 135) does not trust any of media says enough about society in Bosnia and Herzegovina that is directed towards manipulation within its own appearances. In the same time we have present contradiction in adiecto in Latvia when we speak about the same trust to nobody, but in the country of more developed media literacy it can be manifested in that way, only if mentioned understand as something within more commercialization and corporative control of media, in difference from the countries as Bosnia and Herzegovina is where we talk more about direct and/or indirect political control of media of this or that political party.

Basic presumption of possible analyses and also synthesis of presented information and on the basis of received answer on the question "I do analyze information that has been presented to me by the media" is again within diversity of unity, within egocentrism that it is possible to analyze information regardless if you are media illiterate person, or in another words that you analyze you can based on presumption of exclusiveness of your won assumption of understanding that "I know" how to analyze information. In Bosnia and Herzegovina 43,6 \% (81 out of 186) agrees with our question-statement and in Latvia even more $63 \%$ (85 out of 35). 
Through repeating the presumption, the positive manipulation in the case of "comparison of information that has been presented to me by the side of different media" goes down to directing of interviewed towards wanted answers and the fact that interviewed persons in both countries are so much dedicated to the fact that compare information received from different media, although, if we are doing comparison of syntheses with other questions, we come to the confirmation of mentioned even within the indicator that they are doing that because they do not trust media in huge percentage in Bosnia and Herzegovina, while in Latvia we have less case about that. Which confirms that media literacy in this European country is on higher level than in Bosnia and Herzegovina.

"Reading between the lines" within the meaning of "media literacy" and our understanding of it in Bosnia and Herzegovina is more expressive $43 \%-80$ out of 186 (in Latvia 29,8 \% - 39 out of 135) in regards, although we can create logical assumption that this goes more in support to the fact that we want to read "between the lines" instead of reading between the lines because very often it happens that just media texts/articles of any shapes are directing our behavior towards desirable goal and that we are not aware of that at all, and it is especially if we are not conscious within critical observation of individual media texts/information/news. Here we have an issue than in Bosnia and Herzegovina (with the lack of media literacy) people know more to read between the lines than in Latvia, although we came to joint conclusion that the answers were here more sociologically devoted than logically, if we may say that.

Within the question which was asking about the way how we follow media on daily bases, it is really indicative that in Bosnia and Herzegovina, checking information online on Internet is not yet so popular (41,39\%-77 out of 186 in comparison to Latvia where is it $03,3 \%-124$ out of 136), and regardless of really developed Internet network in Bosnia and Herzegovina this can be justified the fact, people more believe traditional media. In Bosnia and Herzegovina TV follows 71,5\% (133 out of 186) and in Latvia 64,1 \% (86 out of 136) and it shows that TV is followed more also in developed countries, still. In the same time we have information that really huge number of people read books within the totality of manifestation (in Bosnia and Herzegovina 41,39\% - 77 out of 186 and in Latvia $44,80 \%-60$ out of 136), although we know that, especially in Bosnia and Herzegovina, due to statistics, reading of the books failed extremely.

Within the statement-question "the future of healthy society is based on..." - foundation of it is on analyses and synthesis of appearances of mentioned issue shows strong direction that citizens consider that the future of healthy society based on "interaction of position and opposition as well as citizens who, through their suggestions, within comprehensive communication, using of media literacy, creates society of sincere and healthy intentions of wellbeing of all members of political community" (Bosnia and Herzegovina - 52,15\% - 97 out of 186 and in 
Latvia 58,30 \% - 77 out of 132). In the same time people in Bosnia and Herzegovina are more directed towards respecting election will of the citizens and that parliament and legal procedures should be executed (in Bosnia and Herzegovina - 24,19\% - 45 out of 186 and less in Latvia - 8,30\% - 11 out of 136). Only seemingly we are able to understand that social-political system is narrowly connected with mentioned, but in front of us open an ocean of possible conclusion when is in question political manipulation within the playing the game with tradition, expected and defense mechanisms of survival in power, when Bosnia and Herzegovina is in question. That is why it happens that in Bosnia and Herzegovina for the almost twenty and more years people elect the same politician who, except for their own benefit, did not do anything for the wellbeing of their own people, and especially not to some citizen from other people as well.

It is an interesting overview of the answers for the question which media citizens use to get information about decisions that comes from the position of higher authority. Namely, there are a lot of causal conclusions from which we put aside only one here where the citizens are directed to TV and Internet to unify information about decisions that comes from the higher level of authority. Traditional and new media are here together within the game. Logical sequence is that in front of us opens unsuspected possibility of positive manipulation directed towards common wellbeing because of the above mentioned (in Bosnia and Herzegovina - TV: 52,7 \% - 98 out of 186 and Internet 36,0 \% - 67 out of 186 and in Latvia - TV is 33,3 \% - 44 out for 132 and Internet: 53,30 \% - 69 out of 132), but as we mentioned earlier, manipulation in this case on the side of creators of media texts/articles of all kinds of shapes which are exactly in Bosnia and Herzegovina on the side of selected politicians, or in other words controlled communication flows with few respectable exceptions which do not define the rule but only makes one minor, meaningless, shape without an influence of manifestation on media field even if we talk about media literacy.

\section{Discussion and future challenges for Latvia and Bosnia and Herzegovina}

The main hypothesis of this case study was that media literacy is basic presumption of the establishing of the society of developed democratic consciousness. At the same, time second another hypothesis appeared as a logical sequence from the title of the paper and refers to political manipulation of the subjects of political pluralism precisely because of the lack of media literacy of society itself in general. The third hypothesis applies to professional intermediaries themselves, journalists and media workers, those specific personality which is located between the public and the source of information. Interweaving and interdependence of the given hypothesis assumed the realisation 
of scientific research on the basis of which we adopted conclusions that methodologically shaped this paper.

Audience, in the most of the case, blindly believe media, in other words, journalists, and many "journalists" are reporting on what they have heard from others, and publish unverified information or even ,alternative facts“ (Hadžialić, 2017). As fans of the journalistic profession we always have to ask ourselves whether the communicated facts credible and how we can interpret it (why something has happened, what are the reasons for it and what will be the consequences)? The basic rule of journalism profession requires that publicly communicated facts be objective, but it allows that their interpretation is different. In professional jargon of journalism this is a rule that in different ways creates presumptions for the creation of the information that are presented, but also responds differently to the news and opinion, commentary even. And again, like it was in the past, due to some interpretation of the facts, the press will be "rewarded", but because of different, will criticized and even punished.

The survey data showed that the majority are aware, however, that the mass media is only a mirror of reality or the constructor of the reality. In this case study it is important to remember that students were involved in the process of survey, so we have to keep in mind sociological and education aspects. As the most represented occupations in Latvian survey were students and employees in the public sector (24.4\% and $38.9 \%$ ), as well as Bosnia and Herzegovina - by 26.9 $\%$ of students and employees in the public sector $-21.5 \%$ and in private -19.89 $\%$. It shows most of them are occupied and educated persons and have understanding about processes of making content of media. The media literacy is the question of media environment and journalistic practice, too. As the effective use of information in society and the need for lifelong learning acquire more and more importance (Koltay 2011; cited from Jolls, Thoman). It is certainly noteworthy, because the younger generation is already accustomed to many different forms and means of communication; they have already developed digital literacy, namely the various technological features and possibilities, as well as free access to information, for the older generation that is what they are learning now; pupils or students have grown with those skills and competence.

The situation of the media in Bosnia and Herzegovina is a combination of censorship, self-censorship, and as it has been called for a long time by the side of media critics on all sides, and creation of media as bulletins, according to which a number of media have a function to transmit the views of individuals to make them more socially acceptable. Theoreticians (Tajić, 2013) from different scientific disciplines (politicology, sociology, communication) has recently engaged in analytical observation of different processes of exactly the understanding of media literacy in the aspect of political manipulation whose common denominator is fragmented cultural, social and political area of Bosnia 
and Herzegovina. However, as states (Tajic, 2013) media literacy in Bosnia and Herzegovina belongs still to the category of pioneering research efforts.

One of the important step in Latvia is that now the media literacy comes into education system. Thus already in school teaching pupils are taught to pay attention how to design and produce, how information is disseminated and how participates in the creation of public space content. Media literacy, if it is in adequate way imported into the society through adequate educational period can be help to define possibilities for the development of the society of immediate democratic consciousness. Exactly the part of our case study is based on mentioned aspect of visualization, identification and shaping of the followers instead of critical observes of one society.

Media literacy empowers people not only to be a focus on being cirtical observes, but also to be creative producers of the unprecedented number of messages using image, language and sound. Communication technologies transform society, they affect the understanding of ourselves, our community, environment (immediate and extended) and our different cultures, making exactly media literacy very important life skills of XXI century

\section{References}

Alvarado, M., Bennett, S., Medison, J., etc. (1997). Media studies in Education. Downloaded from UNESCO: http://unesdoc.unesco.org/images/0002/000238/023803eo.pdf

UNESCO, (2016). News and in focus articles. Downloaded from http://www.unesco.org/ new/en/communication-and-information/resources/news-and-in-focus-articles/allnews/news/unesco_supports_launch_of_an_online_media_ethics_school_in_b/ and YouTube: https://www.youtube.com/watch?v=JzEB_84_Mlk\&feature=youtu.be

Arnett, J. J. (2014). Presidential Address: The Emergence of Emerging Adulthood: A Personal History. Emerging Adulthood. Vol. 2 (3) 155-162.

Brikše, I., Friebergs V., \& Spurava, G. (2013). Media and Information Literacy Policies in Latvia. Downloaded from http://ppemi.ens-cachan.fr/data/media/colloque140528/ rapports/LATVIA_2014.pdf

European Commision (1950). European Convention on human rights and fundamental freedom, 1950. Downloaded from http://www.echr.coe.int/Documents/ Convention_ENG.pdf

International University Travnik (2016). Students of the Faculty of Media and Communications as implementers of surveys for the International projects which is conducting IUT. Downloaded from http://www.iu-travnik.com/v2/index.php/en/vijesti-iut/2112-studentifakulteta-za-medije-i-komunikacije-realizatori-ankete-medunarodnih-projekata-kojeprovodi-iut

Koltay, T. (2011). The media and the literacies: media literacy, information literacy, digital literacy. Media, Culture \& Society, 33 (2), 211 - 221.

Turčilo, L., \& Tajić, L. (2014). Media and Information Literacy Policies in BosniaHerzegovina (2013). Sarajevo: University of Sarajevo. Downloaded from 
Proceedings of the International Scientific Conference. Volume II, May $26^{\text {th }}-27^{\text {th }}$, 2017. 504-518

http://ppemi.ens-cachan.fr/data/media/colloque140528/rapports/BOSNIAHERZEGOVINA_2014.pdf

Mihailidis, P., \& Thevenin, B. (2013). Media Literacy as a Core Competency for Engaged Citizenship in Participatory Democracy. American Behavioral Scientist, 57 (11), 16111622.

Kasapović, M. (2005). Bosna i Hercegovina: podijeljeno društvo i nestabilna država. Zagreb: Politrical culture

O'Neill, B. (2010). Media literacy and communication rights. Ethical Individualism in the New Media Environment. The International Communication Gazette, 72 (4-5), 323-338;

Hadžialić, S. (2013). Bosnia and Herzegovina - European country without Constitution: scientific, ethical and political challenge. Proceedings of the international scientific conference in Sarajevo (ed. Džolan, M.). Downloaded from DIOGEN pro culture, magazine for art, culture, education and science http://www.diogenpro.com/ introspicere_sabahudin-hadzialic.html.

Hadžialić, S. (2017). World As Global Sin: Crippled With Populism And 'Alternative Facts'. Downloaded from http://www.eurasiareview.com/25012017-world-as-global-sincrippled-with-populism-and-alternative-facts-essay/

Meyer, T. (2002). Media Democracy: How the Media Colonize Politics. Cambridge, UK: Polity Press; Malden, MA: Blackwell.

UNESCO (1982). Grunwald Declaration on Media Education. Downloaded from http://www.unesco.org/education/pdf/MEDIA_E.PDF

United Nations (1945). United Nations Charter on human rights. Downloaded from http://www.un.org/en/charter-united-nations/

Vraga, E. K., \& Tully, M. (2016). Effective messaging to communicate news media literacy concepts to diverse public. Communication and the Public, 1 (3), 305-322. 